\title{
Reticularis Thalami Neurons Revisited: Activity Changes During Shifts in States of Vigilance
}

\author{
M. Steriade, L. Domich, and G. Oakson \\ Laboratoire de Neurophysiologie, Département de Physiologie, Faculté de Médecine, Université Laval, \\ Québec G1K 7P4, Canada
}

This study tested the hypothesis that inhibitory actions are exerted by reticularis thalami (RE) neurons upon thalamocortical neurons. The RE neurons were recorded in the rostral pole and lateral districts of the nucleus, and were activated monosynaptically by cortical volleys. Thalamocortical neurons were identified antidromically in intralaminar and ventrolateral nuclei. During sleep with EEG synchronization, prolonged spike barrages of RE neurons extended over the whole spindle sequences. This result suggests that RE neurons are depolarized throughout spindle oscillations, whereas thalamocortical neurons show, simultaneously, long hyperpolarizations and short rebounds. During waking, parallelism rather than reciprocity was found between RE and thalamocortical neurons. Spontaneous discharge rates almost doubled in $R E$ neurons on arousal from sleep, and the probability of cortically evoked short-latency discharges increased. The increase in spontaneous firing rates of RE neurons during natural arousal is consistent with their shortlatency synaptic excitation by stimulating the rostral brain stem reticular formation after chronic degeneration of passing fibers. We suggest that RE cells inhibit GABAergic local-circuit cells, in addition to inhibiting thalamocortical neurons, and that different ratios of inhibitory effects are exerted by $R E$ neurons upon these two cell classes during waking and sleep. We further suggest that, upon arousal, disinhibition of thalamocortical neurons (via the local-circuit neurons) outweighs direct inhibition of the thalamocortical neurons.

The hypothesis that neurons of nucleus reticularis thalami (RE) inhibit relay cells in various thalamic relay nuclei was originally posed both on the basis of connectivity and because of the peculiar burst patterns of RE neurons (Massion et al., 1965; Scheibel and Scheibel, 1967). RE neurons receive afferents from and send projections to almost all thalamic nuclei (Jones, 1975; Ramon y Cajal, 1911; Scheibel and Scheibel, 1966). The peculiar burst pattern of RE cells, first described by Negishi et al. (1962), was regarded as a sign of their inhibitory effects. Additional evidence supporting the hypothesis of RE-mediated inhibition came with the discovery that RE neurons are GABAergic (Houser et al., 1980; Oertel et al., 1983) and that their axonal terminals contain flattened vesicles at symmetrical synapses (Montero, 1983; Montero and Scott, 1981; Ohara et al., 1980, 1983; Pechansky et al., 1983).

Some studies have supported the hypothesis outlined above on the basis that the discharge rates of RE neurons increase during EEG spindle oscillations and decrease during EEG de-

Received Jan. 24, 1985; revised June 3, 1985; accepted July 31, 1985.

This work was supported by Grant MT-3689 from the Medical Research Council of Canada. We wish to thank M. Cardinal, P. Giguère and D. Drolet for technical assistance. Dr J. Hada (Hyogo College of Medicine, Nishinomya, Japan) participated during the early phase of experiments.

Copyright $(1986$ Society for Neuroscience $0270-6474 / 86 / 010068-14 \$ 02.00 / 0$ synchronization induced by midbrain reticular stimulation (Schlag and Waszak, 1971). It is known that thalamocortical neurons behave in an opposite way during both these EEG states (see Steriade and Deschênes, 1984, for a review). The increase in RE neuronal discharge rates during EEG spindling, however, "was not always as clear" (Schlag and Waszak, 1971). Much variability was seen from cell to cell and from spindle to spindle. Furthermore, decreases of firing rates of rostral RE neurons were found during spindling precipitated by small doses of barbiturate (Waszak, 1974). As to the suppressed firing of RE neurons during EEG desynchronization induced by midbrain reticular stimulation (Schlag and Waszak, 1971), the same study reported that when EEG desynchronization was elicited by high-frequency stimulation of medial thalamus, it was accompanied by an intensification of RE firing. Note that the EEG desynchronizing reaction to medial thalamic stimulation is similarly associated with rapid buildup of EPSPs and repetitive discharges in relay neurons of lateral thalamic nuclei (Purpura and Shofer, 1963).

The present investigation was designed to clarify these uncertainties concerning positive or negative correlations in the fluctuations of activity of RE and thalamocortical neurons at various levels of vigilance. It seemed that interpretability of results would be enhanced if the experimental design met certain conditions: (a) The activity of RE neurons must be compared, under the same experimental conditions, to that of identified thalamocortical neurons recorded from relay and intralaminar nuclei, which are important thalamic targets of RE nucleus (Steriade et al., 1984). The best situation for studying natural arousal and spindling is in the chronically implanted, behaving animal. (b) In addition to firing measurements during "steady" states of wakefulness (W) and slow-wave sleep (S), spontaneous discharges should be examined sequentially in order to relate RE neuronal discharges to the key events under consideration, namely, the spindle sequences and the EEG desynchronization on arousal from $S$, when the most dramatic changes are expected to occur. (c) As the analysis of spontaneous discharges is insufficient for assessing cellular excitability, a more satisfactory way to examine a cell's excitability during $W$ and $S$ is the use of central testing volleys that induce monosynaptic responses. This avoids unknown modifications at intercalated synapses when using peripheral stimuli.

This paper attempts to meet these methodological requirements and, in so doing, to provide an answer to the question of the nature of the actions of RE neurons on thalamic relay neurons during sleep and waking.

\section{Material and Methods}

Preparation, stimulation, recording

Chronic experiments were conducted on 17 adult cats of either sex. Surgery for implantation of stimulating and recording electrodes was 

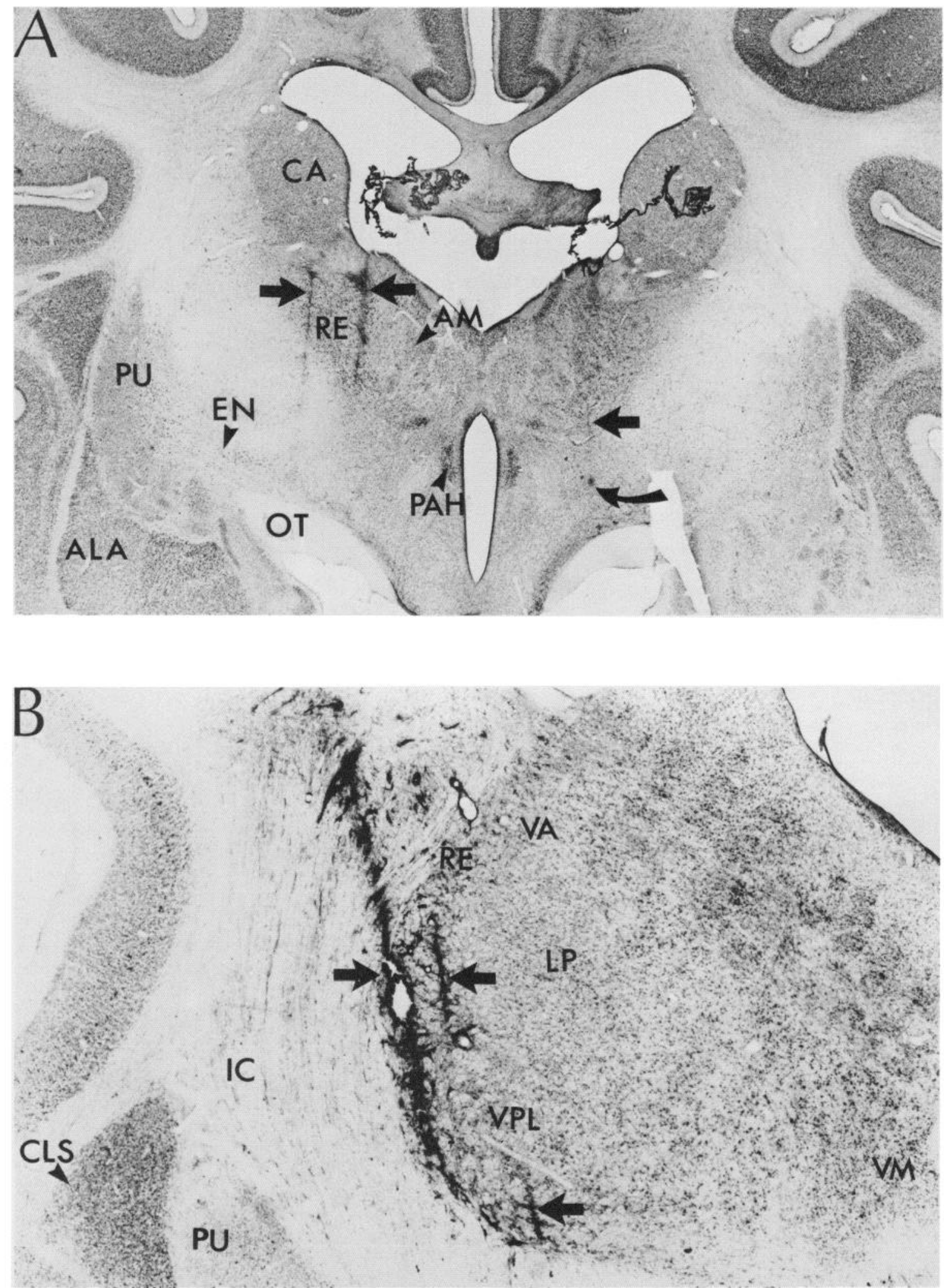

Figure 1. Microelectrode tracks in the rostral pole $(A)$ and lateral part $(B)$ of RE nucleus. Frontal sections. Tracks are indicated by heavy arrows; in $A$, oblique arrow at right indicates a small electrolytic lesion at the bottom of the track; in $B$, two tracks passed through the VPL nucleus in addition to the most lateral track through the RE nucleus. $A L A$, lateral nucleus of amygdala; $A M$, anteromedialis nucleus; $C A$, caudate nucleus; $C L S$, claustrum; $E N$, entopenduncular nucleus; $I C$, internal capsule; $L P$, lateralis posterior nucleus; $O T$, optic tract; $P A H$, paraventricular hypothalamic nucleus; $P U$, putamen; $V A$, ventralis anterior nucleus; $V M$, ventralis medialis nucleus; $V P L$, ventralis posterolateralis nucleus. 


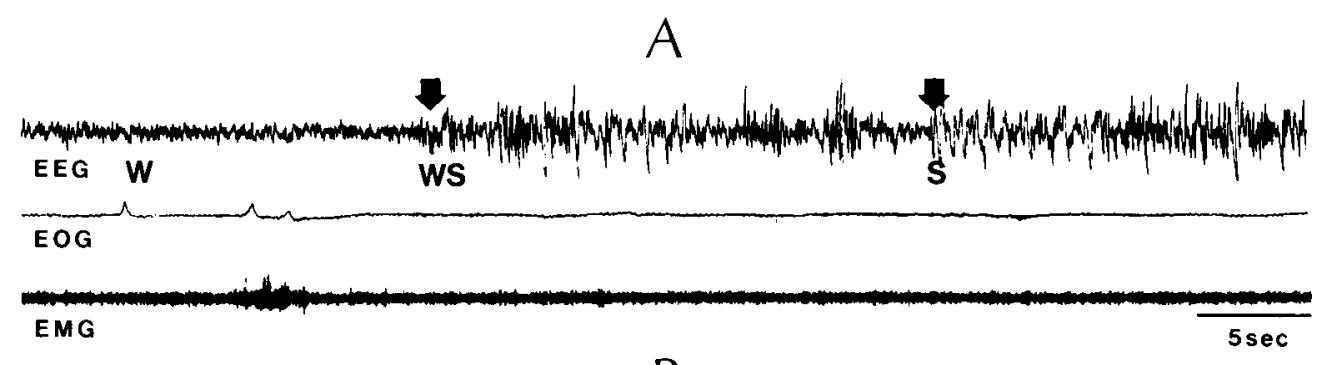

Figure 2. Electrographic criteria of wake $(W)$ and slow-wave sleep $(S)$ states. $W S$ and $S W$ are transitional states between $\mathrm{W}$ and $\mathrm{S}$, and $\mathrm{S}$ and W. $A, B$, EEG waves from the surface of precruciate gyrus, ocular movements $(E O G)$, and electromyogram of neck muscles $(E M G)$. Note appearance of spindle sequences during WS and repeated desynchronizing reactions; $\mathrm{S}$ begins when slow-waves also appear and EEG desynchronizations no longer occur. $C$, Normalized amplitudes (ordinates) of simultaneously recorded focal waves in the thalamus (top line-circle trace, MSP, filtered to frequency range of spindle waves, 7$14 \mathrm{~Hz}$ ), cortical spindle waves (bottom line-circle trace, CSP, filtered to $7-14 \mathrm{~Hz}$ ) and cortical slow-waves (bottom bar graph, CSA, filtered to $0.5-4 \mathrm{~Hz}$ ). Abscissa indicates real time. For further details, see text. Note desynchronization (decreased wave amplitudes), on awakening, from $S$ to $S W$ and further to $W$; slow rhythmic spindle sequences (period ca. 8-10 sec) in both thalamic and cortical recordings, beginning with WS (curved arrows); increased amplitudes of both spindles and slow-waves, without transient desynchronizations, beginning with $\mathbf{S}$.

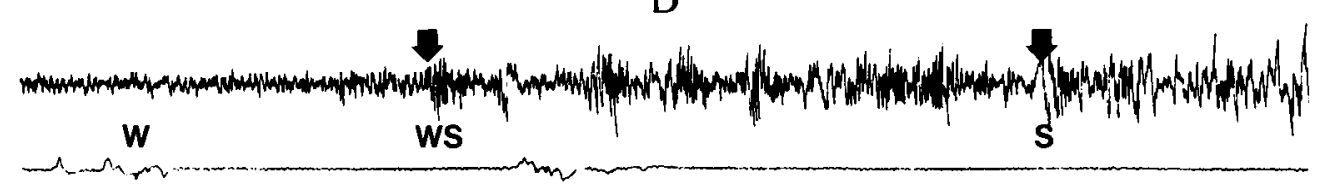

performed under sodium pentobarbital anesthesia $(35 \mathrm{mg} / \mathrm{kg})$. The method used, which allows microelectrode penetrations with the head rigidly held in a stereotaxic position without pain or pressure, was the same as in our previous studies on thalamic neurons (Steriade and Glenn, 1982). Recording leads consisted of several screws threaded into the skull, or silver-ball electrodes on the cortical surface for recording EEG rhythms; silver-ball electrodes for ocular movements (EOG); and electrodes for neck muscle potentials (EMG). Two arrays of bipolar stimulating electrodes made from used microelectrodes (each consisting of four to six wires with tips bared 0.1 to $0.3 \mathrm{~mm}$, about $1-1.5 \mathrm{~mm}$ apart) were inserted in deep layers or the white matter underlying pericruciate gyri. We used two adjacent cortical wires, effective for monosynaptic activation of RE neurons, to record EEG rhythms bipolarly in a rather circumscribed area directly connected to the explored RE unit. In six animals, an array of three to four wires ( $1 \mathrm{~mm}$ apart) was implanted into the midbrain reticular formation. To stimulate midbrain reticular neurons after chronic degeneration of passing fibers, electrolytic lesions were made bilaterally in the locus coeruleus (two animals) and ipsilaterally covering the whole pontine tegmentum or the pontomesencephalic transition zone (four animals; see Fig. 12). Recordings began 10-14 d after lesions or a week after chronic implantation in animals without lesions. The animals were not deprived of sleep between recording sessions.

Cortical and brain stem stimulations $(0.05-0.2 \mathrm{msec}$ pulses, usually $0.05-0.2 \mathrm{~mA}$, delivered at 1 or $2 \mathrm{sec}$ intervals) were applied below the threshold for movements and did not disturb the normal wake-sleep cycle. There was no behavioral sign that electrical stimulation was experienced. Single neurons were extracellularly recorded by means of tungsten microelectrodes (1-2 $\mu \mathrm{m} ; 1-5 \mathrm{M} \Omega$ at $1 \mathrm{kHz}$ ) inserted into the rostral pole (Fig. $1 A$ ), rostrolateral and lateral parts of the RE nuclear complex (Fig. $1 B$ ), as well as in rostral intralaminar centralis lateralisparacentralis (CL-PC) nuclei and in ventralis anterior-ventralis lateralis (VA-VL) nuclei. Presumed fibers (exceedingly short, $<0.8 \mathrm{msec}$, exclusively positive discharges) and neurons with signs of injury (notched spikes, with unusual high rates) were disregarded. Unit discharges and focal slow waves were recorded simultaneously by the microelectrode on direct $(50-10,000 \mathrm{~Hz})$ and FM $(1-700 \mathrm{~Hz})$ channels of a tape recorder, along with trigger stimulation pulses and EEG-EOG-EMG variables indicating the state of vigilance. Ten to 15 descents were made in each animal. After successful descents, small lesions (10-20 $\mu \mathrm{A}, 20-30$ sec) were made at one or two sites along the tracks. At the end of the experiment, the animals were deeply anesthetized with sodium pentobarbital and perfused intracardially with 0.5 liter of saline and 1 liter of $4 \%$ formaldehyde. The stimulating electrodes, microelectrode tracks, and extent of brain stem lesions were examined in frontal frozen sections ( 50 or $80 \mu \mathrm{m}$ ) stained with cresyl violet or thionine (Fig. 1). The location of recorded neurons in various thalamic nuclei was possible by combining lesion sites along tracks with micrometer readings.

\section{Analyses}

Electrographic criteria of behavioral states of vigilance were similar to those used in a previous study on midbrain reticular neurons (Steriade 


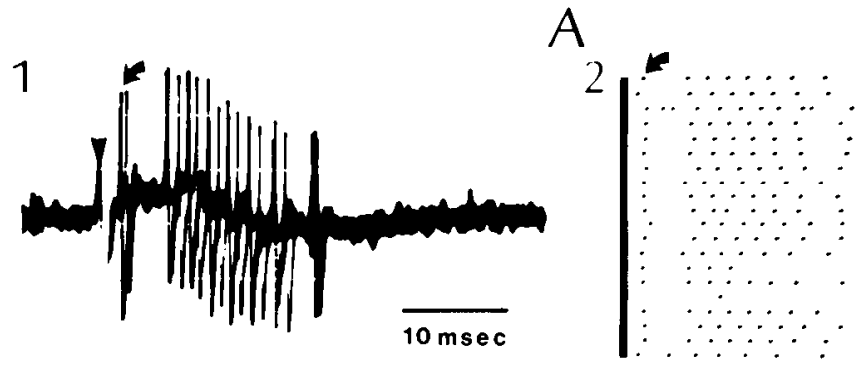

3 RESP

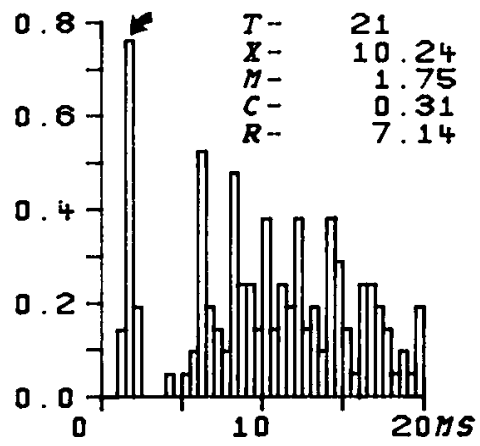

B
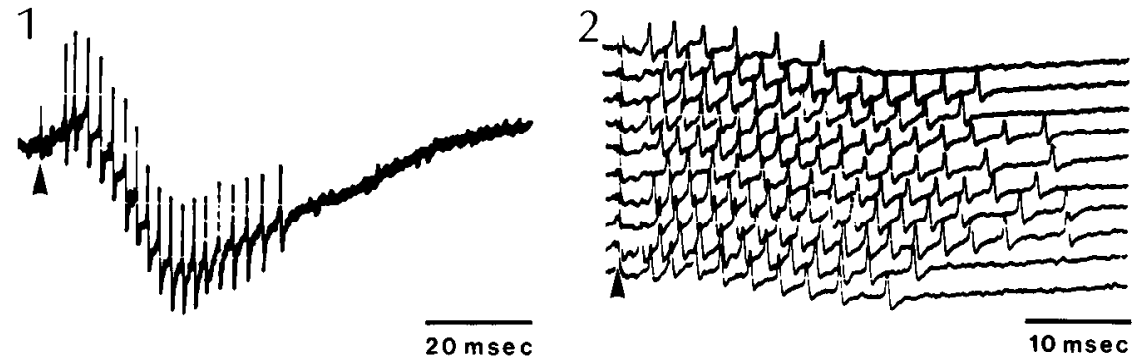

Figure 3. Physiological identification of RE neurons. Two different neurons recorded in the rostral pole $(A)$ and lateral, peri-VPL part $(B)$ of RE nucleus. Single-shock stimulation in the precruciate $(A)$ and postcruciate $(B)$ gyrus during $\mathrm{S}$ sleep. Stimulus, marked by arrowheads, vertical bar (in $A$ 2) was applied at time 0 in $A 3$. $A$, Several superimposed traces (l), 20-sweep dotgram (2), and poststimulus histogram PSH with $0.5 \mathrm{msec}$ bins (3). $T$, Number of trials; $X$, mean latency (in msec); $M$, latency mode; $C$, coefficient of variation; $R$, sum of all bin responsiveness (number of spikes per bin divided by number of trials). $B$, Single-sweep and 10 -sweep sequence with reduced gain. In this and similar figures, positivity is downward. et al., 1982). Measurements of spontaneous discharge rates during $W$ did not include periods $(>2 \mathrm{sec}$ ) with overt movements, since motor events may introduce uncontrolled factors due to the proprioceptive drive generated by movement itself. The following states were analyzed (Fig. 2). Quiet W was accompanied by continuous EEG desynchronization. The intermediate state between W to $S$, termed WS, began at the first high-amplitude sequence of spindle waves $(7-14 \mathrm{~Hz})$, continued with rhythmically recurring spindle sequences (Fig. $2 C$ ), and eventually led to $\mathrm{S}$; this transitional period was associated with repeated closing and reopening of animals' eyes and comprised transient shifts from EEG desynchronization to synchronization and vice versa. The state of $S$ sleep, with spindles $(7-14 \mathrm{~Hz})$ and slow $(0.5-4 \mathrm{~Hz})$ waves started at the time at which EEG synchronization was no longer interrupted by desynchronization periods. Awakening from $S$ occurred either abruptly with all electrographic and behavioral signs of $W$, or after a transitional period (SW). The beginning of SW (i.e., the end of S) was defined as the earliest sign of decrease in amplitude and increase in frequency of EEG rhythms that must eventually lead to a generalized EEG desynchronization and behavioral arousal.

In addition to visual inspection of original electrographic recordings, changes in states of vigilance were emphasized by plotting EEG-wave average amplitudes as a function of time (Fig. $2 C$ ). Filtered spindlewave amplitudes $(7-14 \mathrm{~Hz})$, recorded focally by the thalamic microelectrode (top line-circle trace, MSP) were displayed with simultaneously recorded cortical rhythms, consisting of filtered spindle waves (7-14 $\mathrm{Hz}$; bottom line-circle trace, CSP) and slow-waves $(0.5-4 \mathrm{~Hz}$; bottom bar-graph trace, $\operatorname{CS} \Delta$ ). Amplitudes were normalized between the highest value found in $S(100 \%)$ and the lowest amplitude in $W(0 \%)$. To preserve relative amplitudes between cortical spindles and slow-waves, the two channels were normalized to the highest value of both channels. Data were obtained by applying each filtered EEG signal to a full-wave rectifier and a voltage-controlled oscillator with a resting frequency of $500 \mathrm{~Hz}$. The number of oscillations during consecutive $0.5-$ or $1-\mathrm{sec}$ periods was taken as a measure of mean EEG amplitude. For each analyzed neuron, sequential mean frequency (SMF) of unit discharges were counted, along with simultaneously recorded focal thalamic and cortical EEG waves. To avoid any detrimental effects of short-term noise, the data were filtered for plotting by a 3-bin equally weighted moving average (see such data with RE unit discharges and various types of EEG rhythms in Figs. 6 and 7).

As a rule, measurements of spontaneous discharge rates were made from epochs completely free of testing shocks. That is, the firing rate was quantitatively measured during one or several wake-sleep cycles, different from when its synaptic excitability was determined. Changes in spontaneous firing rates related to the behavioral state of vigilance did not, however, differ qualitatively in periods with or without testing stimuli. The weighted, pooled mean rate for a given state was computed for each cell by summing the number of spikes for all available periods in that state and dividing by the sum of period durations. The nonweighted mean rate of a given neuronal sample for each state was then computed by averaging all cell mean rates in that state. Significance levels of rate differences between states were computed by using Wilcoxon paired signed-rank tests. Analyses of group data related to onset of spindles (Fig. 8) and arousal (Fig. 10) will be explained in Results.

Synaptic responsiveness was assessed from multiple sweep displays and poststimulus histograms. 

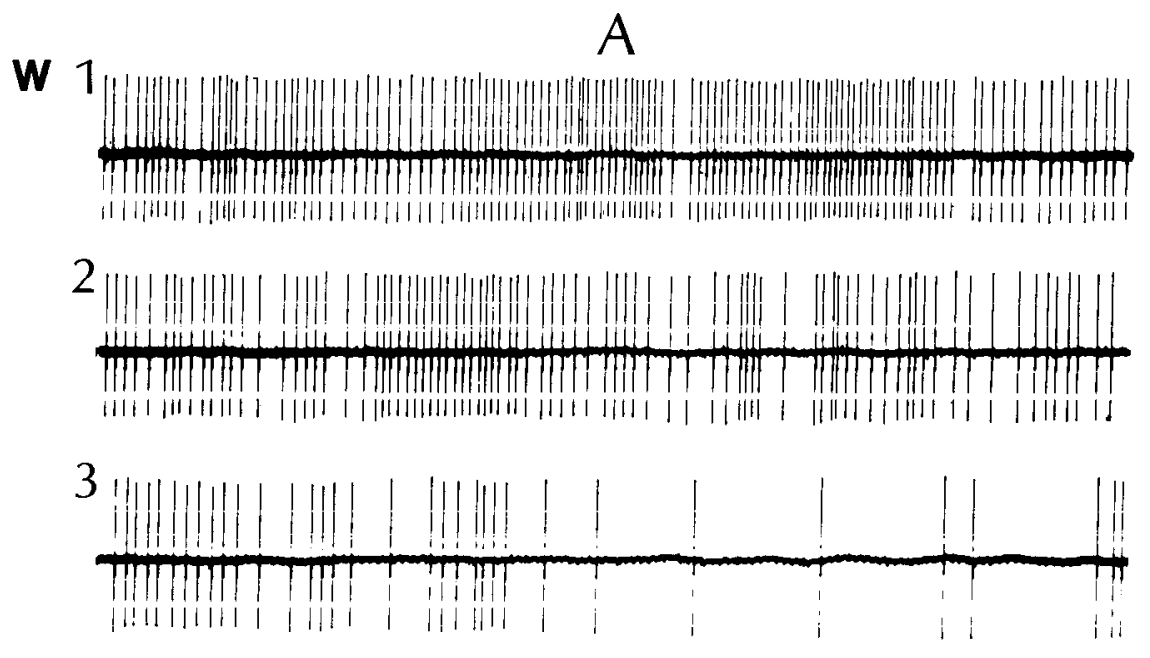

$\mathbf{S}$

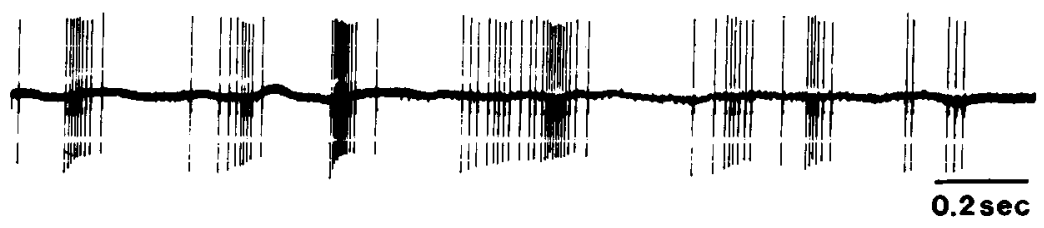

Figure 4. Discharge characteristics of RE neurons during $W$ and $S$ states. Two neurons recorded in the rostral pole $(A)$ and rostrolateral, peri-VA part $(B)$ of RE nucleus. $A$, Three epochs are illustrated during $W$ : from the onset of arousal from $S(I)$; in the middle part of W (2; $15 \mathrm{sec}$ after 1); and at the end of W state, just before WS ( 3 ; $11 \mathrm{sec}$ after 2). Discharge rates progressively decreased from 1 (around $60 / \mathrm{sec}$ ) to 2 (around 45/sec) and finally (3) reached 6/sec. Mean firing rate during the whole $W$ state was in this case $34.9 / \mathrm{sec}$, and $20.0 / \mathrm{sec}$ in $\mathrm{S}$. $B$, The top trace in $\mathrm{S}$ is depicted at higher gain and faster speed to show details of burst structure. Mean firing rate in $S$ and $W: 30.9$ and $21.2 / \mathrm{sec}$, respectively.

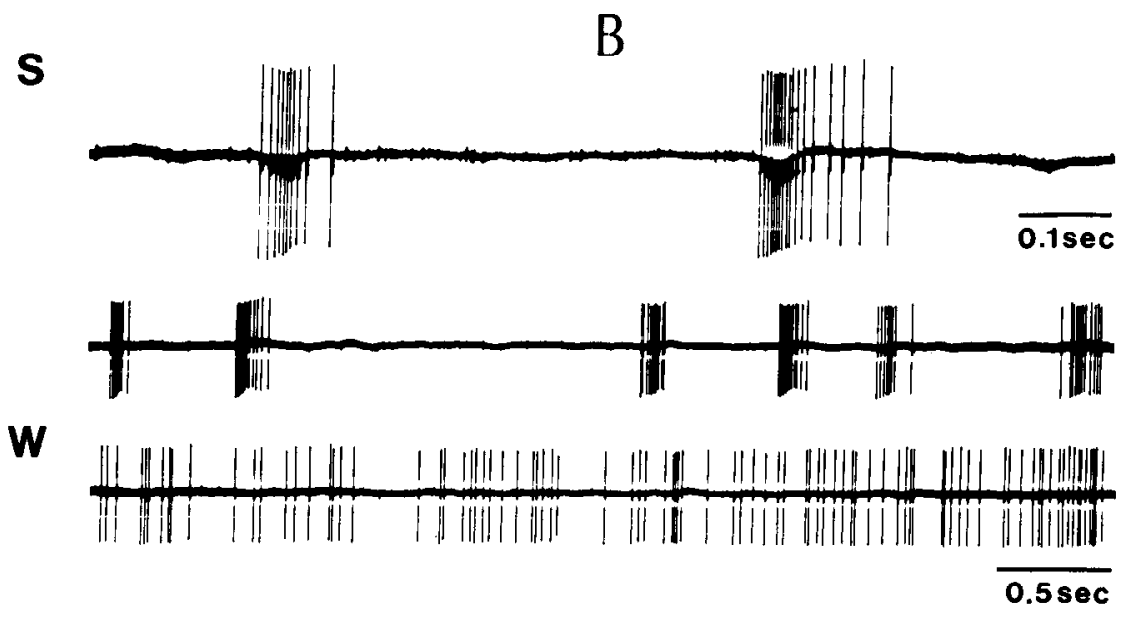

\section{Results}

\section{Data base and neuronal identification}

Spontaneous firing and synaptic responsiveness were investigated in about $350 \mathrm{RE}$ neurons during $\mathrm{W}$ and $\mathrm{S}$ states. Of them, 65 could be recorded for sufficient periods of time in both behavioral states to be included in statistical analyses of spontaneous and evoked discharges. The remaining neurons exhibited activity patterns similar to those analyzed quantitatively.

In addition to their location within the histological limits of RE nucleus, RE neurons were identified by their peculiar synaptic responses. In response to a cortical volley, they discharged during S sleep with high-frequency $(250-400 / \mathrm{sec})$ spike bursts lasting $25-40 \mathrm{msec}$ (Fig. 3). During S, the latency of burst onset varied between 2 and $8 \mathrm{msec}$. The monosynaptic excitatory nature of the cortico-RE connection became evident during the W state, when the same neurons shortened the response latency to $<2$ msec (see Fig. 11). In some neurons recorded from the rostral pole of RE nucleus, the cortically elicited response consisted of two distinct parts: a single discharge with a latency of $1.5-2 \mathrm{msec}$, followed by a $500 / \mathrm{sec}$ burst (Fig. $3 A$ ). The first, single spike may be ascribed to antidromic activation of fastconducting thalamocortical axons that collateralize and synaptically excite RE neurons, while the subsequent protracted burst is attributable to the long-lasting excitation exerted by cortico-RE fibers.

In order to compare the activity of RE neurons and thalamocortical neurons during $\mathrm{W}, \mathrm{S}$, and intermediate states, we identified in the same experiments $20 \mathrm{CL}$ neurons and $19 \mathrm{VL}$ neurons by their antidromic invasion from pericruciate cortical areas. Standard criteria for antidromic responses were used: fixed latency, collision with spontaneously occurring action potentials, and high-frequency following. The antidromic response latencies and the inferred conduction velocities of thalamocortical cells (medians: $11.2 \mathrm{~m} / \mathrm{sec}$ for CL neurons, $13.5 \mathrm{~m} / \mathrm{sec}$ for VL neurons) were similar to those reported in our previous studies on CL (Steriade and Glenn, 1982) and VL (Steriade et al., 1971) neurons.

\section{Spontaneous activity}

General discharge characteristics. The single-spike, tonic discharge pattern of $R E$ neurons during $W$ was similar to the ac- 
A
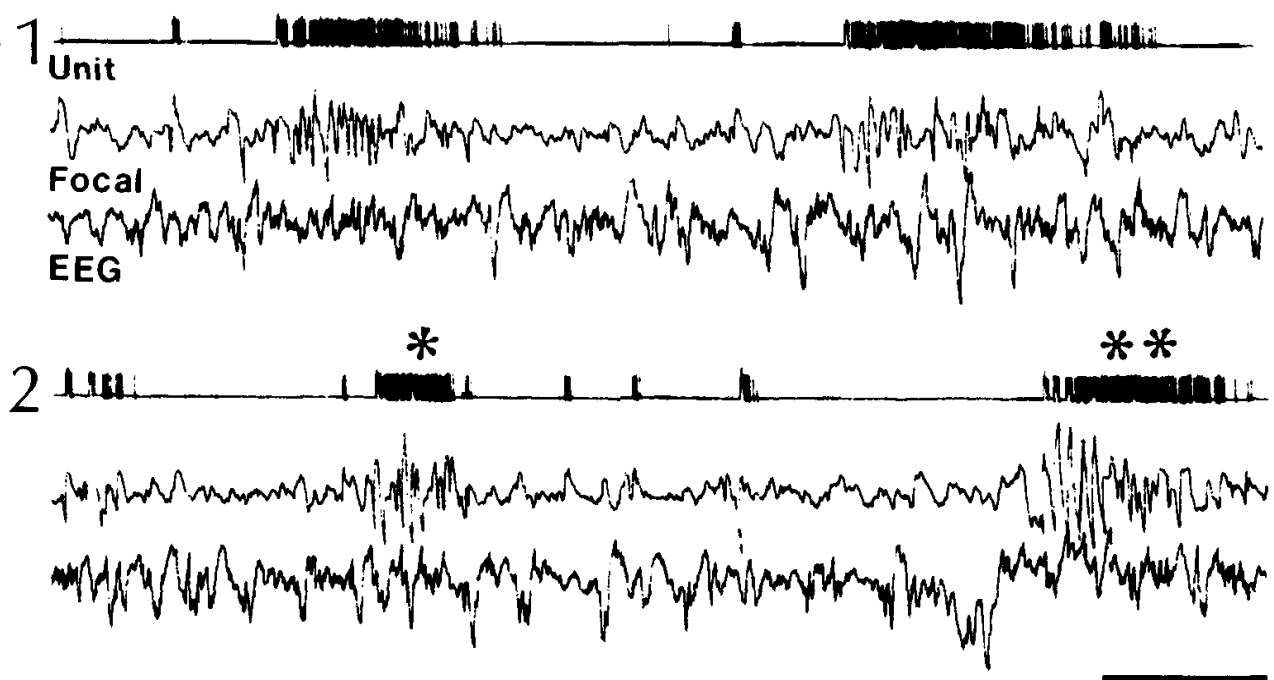

$2 \sec$
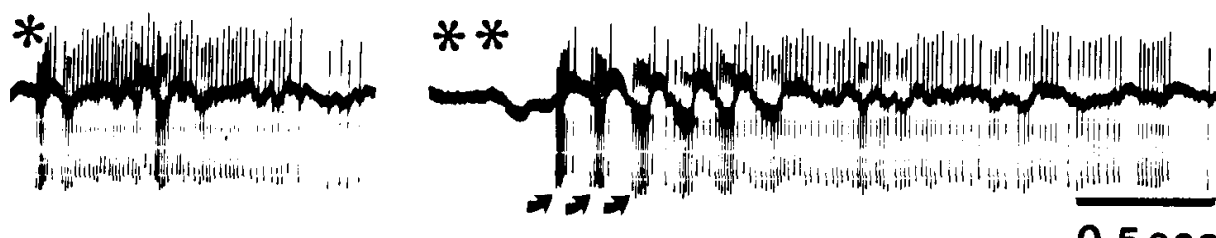

$0.5 \mathrm{sec}$

$\mathbf{B}$
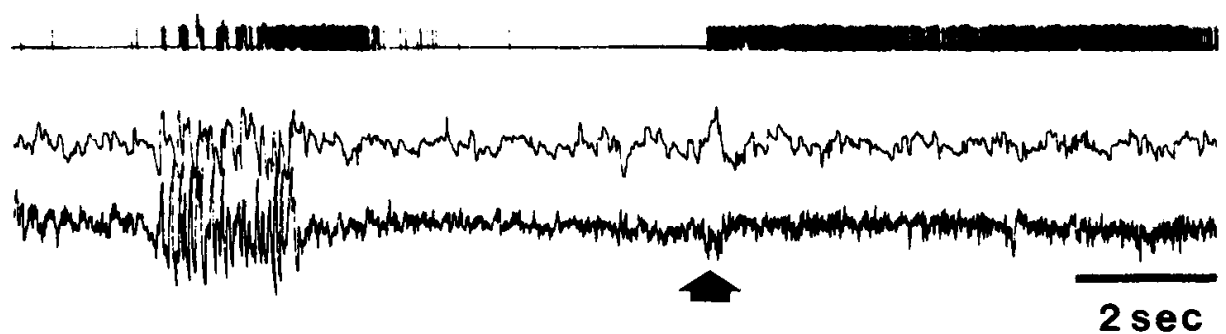

$C$

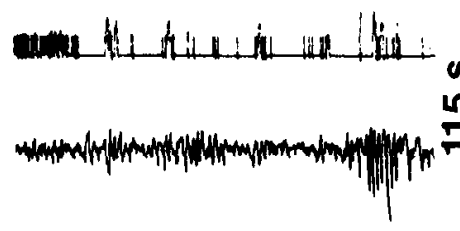

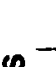
Whin L_L (<smiles>c1ccccc1</smiles>

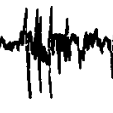

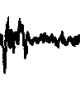

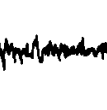

Figure 5. Relations between spike barrages of RE neurons and spindle sequences. $A-C$, Three different neurons in the rostral pole of RE nucleus. $A$, Three ink-written traces in both $I$ and 2 are unit discharges, focal waves recorded simultaneously through the same microelectrode, and EEG waves recorded bipolarly between suprasylvian and lateral gyri. The two oscilloscopic traces depict two spike barrages, as indicated in 2 . Note (in double asterisk barrage) initial, repetitive spike bursts (arrows) in close relation with focal spindle waves at $7.5 \mathrm{~Hz} . B$, Focal RE-wave (as in $A$ ) and corticalwave amplitude recorded from the electrode pair in the depth of the precruciate gyrus used to activate the RE neuron. Sensory (sound) arousal elicited at arrow. $C$, Same recording of EEG waves in the precruciate gyrus as in $B$ (see the pattern of monosynaptic activation of this RE neuron in Fig. 3A); spontaneous arousal at arrow. tivity of thalamocortical neurons during the same behavioral state. The characteristic sign of RE cells was their spike barrages during $S$ sleep, which clearly distinguished them from thalamocortical neurons. The RE spike barrage was exceedingly long (50-500 msec, but often as long as 1-2 sec); the intraburst frequencies were between 80 and $180 \mathrm{~Hz}$; and discharges typically exhibited an initial acceleration followed by deceleration (Fig. 4). In $15 \%$ of RE neurons with very long spike barrages, the initial acceleration was repetitive and took the form of phasic, distinct bursts, each of them associated with one wave of the focal spindle sequence at about 7-8 $\mathrm{Hz}$ (see double asterisk in Fig. $5 A$ ). As such, the bursts of RE neurons stood in contrast with short (10-25 msec) and high-frequency $(>250 \mathrm{~Hz})$ bursts of thalamocortical cells. The great variability seen in consecutive RE bursts (Fig. 4) also contrasted with the stereotyped bursts of relay cells, which show little variation in a given neuron.
The change from tonic firing in $W$ to burst discharges interspersed with long periods of silence in $S$ was the stigmatic event of RE neurons and it occurred invariably, regardless of changes in firing rates. As shown below with quantitative measurements, most RE neurons diminished their firing rates from $W$ onset to the last period of $W$, and further slowed down the discharge frequency toward sleep (Fig. 4A). Some RE neurons, however, displayed the same tonic-vs-burst patterns in $\mathrm{W}$ and $\mathrm{S}$, but firing rates were lower in W (Fig. $4 B$ ). Testing the excitability of the latter elements indicated that, in spite of their decreased rates of spontaneous discharge during $\mathbf{W}$, these fewer elements had, in the same state, an enhanced synaptic responsiveness at short latencies.

Relation of $R E$ burst discharges to focal spindling during sleep. Simultaneous recording of unit discharges and focal waves through the same microelectrode afforded information on tem- 

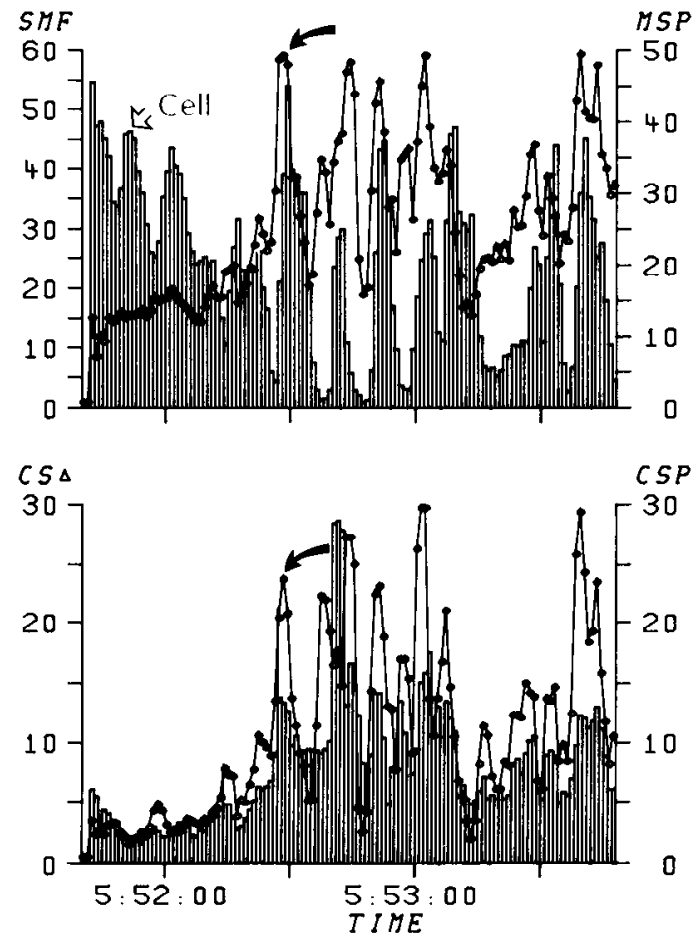

Figure 6. Sequential RE-cell firing, RE focal spindles, and cortical EEG amplitudes during transitions in wake-sleep states. Neuron in rostral pole of RE nucleus. Same indications for focal thalamic (top line-circle traces) and cortical EEG (bottom line-circle and bar graph) rhythms, as in Figure $2 C$. In addition, the spontaneous discharges of RE neuron are depicted here (top bar graph); left ordinate indicates sequential mean frequency $(S M F)$. Note rhythmic oscillations $(0.1-0.2 \mathrm{~Hz})$ in cell firing associated with focal and cortical spindle sequences (oblique arrows) in transitional period from $W$ to $S$ (overt signs of focal and cortical EEG synchronization visible at $5 \mathrm{hr}, 52 \mathrm{~min}, 30 \mathrm{sec}$ ).

poral relations between spike bursts and spindle sequences during $S$ sleep. As a rule, spike barrages of individual RE cells were closely related to focal spindle waves representing 7-14 Hz oscillations in a pool of neighboring RE neurons. This can be seen in Figure 5, with long spike barrages (1-2 sec, in A and B) or shorter-duration bursts (50-200 $\mathrm{msec}$ in C). Quite discrete relations may be seen between the initial components of a RE spike barrage and the individual waves of the focal spindle sequence (Fig. $5 A$, double asterisk). When EEG was recorded between two distant screws threaded in the skull, the relation between RE bursts and cortical spindle activity was much less clear than the association between RE unit discharges and focal RE spindling (Fig. 5A). When, however, EEG rhythms were recorded between the deep cortical electrodes that served for synaptic activation of the investigated cell, the RE spike barrage occurred in a good time relation with both spindle sequences recorded focally in the RE nucleus and the cortical focus (Fig. $5 B)$.

The spindle-burst relation and the recurrence of both field and unit events with a slow rhythm at $0.1-0.2 \mathrm{~Hz}$ became clear during shifts in the vigilance level when digitized and displayed sequentially over several minutes (Figs. 6 and 7). In such analyses, with 3-bin moving averages, the details of short-term intraburst structure were lost. The evolution from $W$ to drowsiness is shown in Figure 6: the firing rate of the RE neuron progressively slowed down toward the end of the W state, and thereafter, burst discharges peaked every 5-10 sec, together with spindle sequences recorded focally in the RE nucleus. The rhythmic recurrence of spindle and burst episodes at $0.1-0.2 \mathrm{~Hz}$ was associated with a similar rhythmicity in the cortical focus whence orthodromic activation of the neuron was elicited. The statespecificity for spindle-burst relation is shown in Figure 7: a short period of arousal with blockade of spindle oscillations was associated with replacement of rhythmic spike bursts by sustained firing.

To provide evidence for positive relations between $\mathrm{RE}$ spike bursts and focal spindle sequences, we analyzed 334 bursts of 14 RE cells chosen by computer according to three criteria: at least 10 bursts occurred during each analyzed $\mathrm{S}$ epoch, burst duration $\geq 250 \mathrm{msec}$, and interburst period $\geq 1 \mathrm{sec}$. Time 0 in Figure 8 is the onset of bursts rounded to the start of the nearest bin (possible individual timing error: $\pm 0.25 \mathrm{sec}$ ). The comparison between the first $0.5 \mathrm{sec}$ bin after burst onset (arrows) and preceding or subsequent bins shows statistically significant differences in both discharge rates of RE neurons and relative amplitudes of 7-14 $\mathrm{Hz}$ spindle waves recorded focally by the same microelectrodes.

Increased discharge rates on awakening. The above data showed that RE neurons increased their discharge rates upon spontaneous or sensory-elicited arousal from S sleep and, conversely, decreased discharge rates from a high level of vigilance during arousal to drowsiness (see Figs. 5 and 6).

We analyzed firing rates during $W, S$, and the intermediate WS state in a sample of 32 RE neurons, and compared them with data from $20 \mathrm{CL}$ and $19 \mathrm{VL}$ thalamocortical neurons recorded in the same experiments during similar behavioral states (Fig. 9). The results showed that (a) Most (23 out of 32) RE neurons decreased their firing rates from W to WS. In the whole 32-cell sample, median and mean discharge rates were reduced by $28-30 \%$, the difference being highly significant $(p<0.002)$. The decrease in firing rates from $\mathrm{W}$ to $\mathrm{S}$ was significant at $p<$ 0.03 ; (b) similar results were obtained in thalamocortical neurons. In the CL and VL samples, 16 of 20 and 18 of 19 neurons, respectively, decreased firing rates from $W$ to WS.

Aside from these similarities between RE and thalamocortical cells, some differential features should also be considered. One of them concerns the high discharge rates of RE neurons during S sleep (median slightly above 19/sec)-two and three times higher than the rates of VL and CL neurons during the samc state. This high level of discharge is ascribable to the extremely long spike barrages of RE neurons during $S$ sleep. The other feature is the very high discharge rates that $R E$ neurons display upon arousal from sleep. Note that firing rates depicted in the W column in Figure 9 were taken from the whole W state, thus concealing a progressive slowing down of discharge frequencies from the onset to the end of $W$. In a subsample of $18 \mathrm{RE}$ neurons from the above 32-cell sample, selected because they could be recorded for $W$ epochs of at least $30 \mathrm{sec}$, the first $10 \mathrm{sec}$ period (i.e., the initial period, corresponding to arousal from $S$ sleep) was compared to the middle and last $10 \mathrm{sec}$ periods. The results showed a progressive decrease in firing rates from arousal toward drowsiness. Differences between discharge rates during the first $10 \mathrm{sec}$ period of $W$ and during the second and third $10 \mathrm{sec}$ periods were significant at $p<0.006$ and $p<0.001$, respectively. Some neurons reached firing rates of $90-100 / \mathrm{sec}$ for about $20 \mathrm{sec}$ upon arousal from sleep and continued thereafter to discharge at $50-70 / \mathrm{sec}$ for another period of $20 \mathrm{sec}$. Such discharge levels were not seen in thalamocortical cells.

Fourteen RE neurons were analyzed as a group, on a bin-bybin basis, during 24 epochs of S-to-W transitions, along with changes in the simultaneously recorded focal RE spindle waves, as well as cortical spindles and slow-waves. The result (Fig. 10) shows that RE neurons double their discharge rates on arousal, which is associated with the desynchronization of focal and cortical EEG rhythms. 

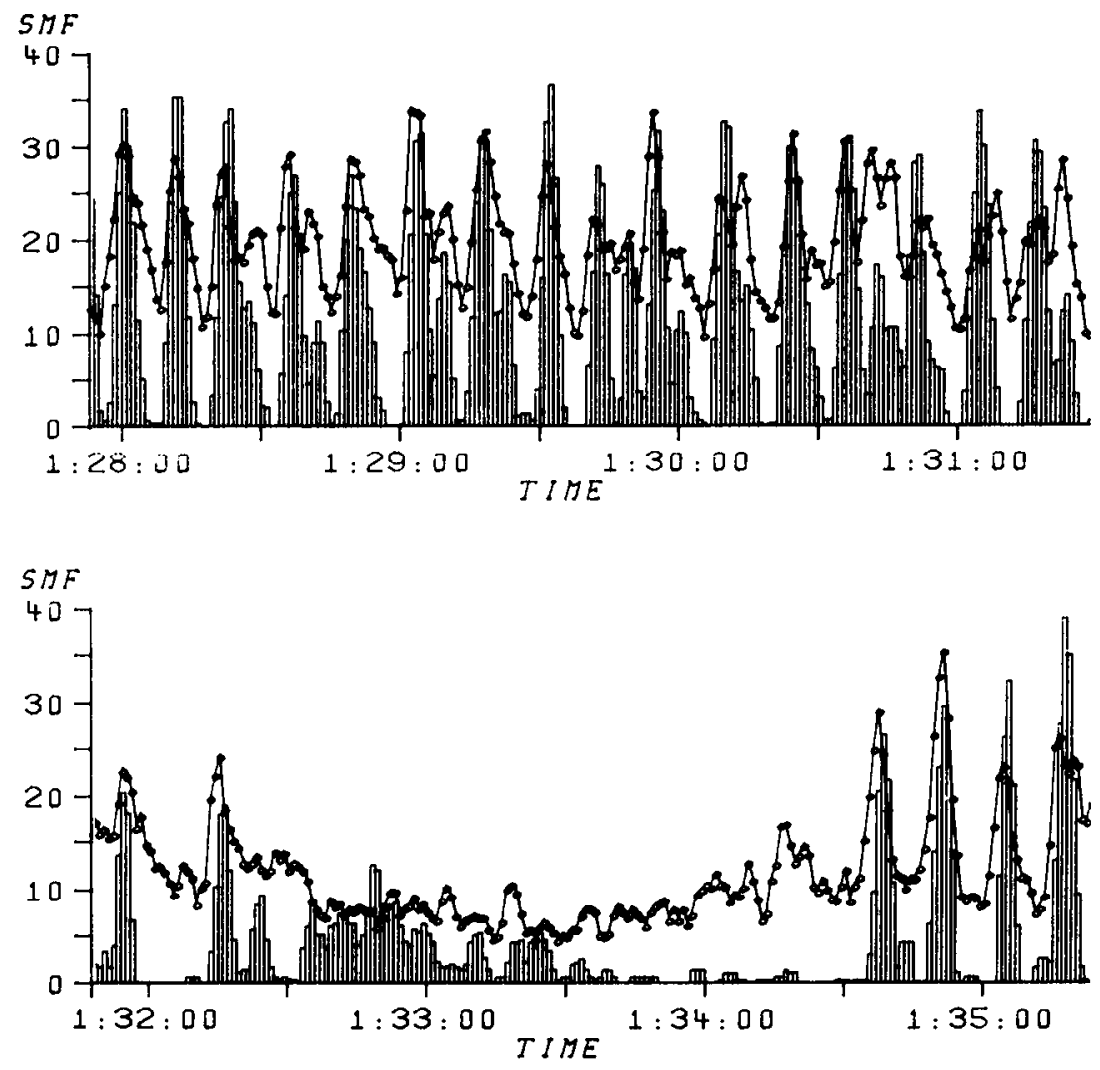

Figure 7. State (S)-specificity of rhythmic spike barrages and related focal spindle oscillations. Sequential mean frequency $(S M F)$ of discharge in a rostral RE neuron (same type of computer-made graph as in top part of Figure 6). Top, S sleep. Bottom, Short period of arousal at 1:32:30; reappearance of rhythmic events during $S$ at 1:34:35.

\section{Excitability tests}

Cortically evoked discharges. Changes in RE discharges evoked by cortical stimulation during $\mathrm{W}$ and $\mathrm{S}$ states were studied in 28 neurons. Lack of significant alterations from one state to another was observed in only three cells. In all remaining 25 neurons the changes during $W$ consisted of an increased probability of discharges elicited at short latencies, while during $S$ the total duration of the evoked burst was considerably increased. The same basic pattern was obtained in all neurons regardless of differing changes in the spontaneous firing of various cells from $\mathrm{W}$ to $\mathrm{S}$. Figure 11 shows that discharges evoked at less than 2 msec latency increased by about $125 \%$ in $W$ compared to $\mathrm{S}$. The duration of the evoked burst, however, doubled in S, reaching $50 \mathrm{msec}$. Also, during S, two grouped excitations occurred at 200 and $400 \mathrm{msec}$; during W, after a period of diminished firing lasting $125 \mathrm{msec}$, spontaneous discharges resumed at the prestimulus level.

Responses to midbrain reticular stimulation. Stimulating electrodes were located in the caudal or rostral part of the midbrain reticular formation (MRF) in animals with bilateral lesions of locus coeruleus (Fig. 12, $A, B$ ). In the caudal midbrain, the stimulation site overlapped with the peribrachialis and so-called pedunculopontine nuclei. In animals with ipsilateral lesions in the transitional zone of pontine-midbrain tegmentum (Fig. 12C), the rostral MRF was stimulated. Similar MRF-induced effects in RE neurons were obtained in both types of experiments.

As single-shock stimulation was not effective in modifying RE-cell activity, we used double- or three-shock trains. Two distinct types of MRF-evoked responses were obtained in 27 tested RE cells. (1) Short-latency ( $<5 \mathrm{msec}$ ) excitation was seen in 22 neurons recorded from either rostral pole or lateral parts of RE nucleus. The response characteristics were state-dependent (Fig. 13). During W, the latencies of short bursts (2-3 spikes) were grouped between 4 and $10 \mathrm{msec}$, with modes around 6 msec. A secondary, minor excitation occurred during $W$ and

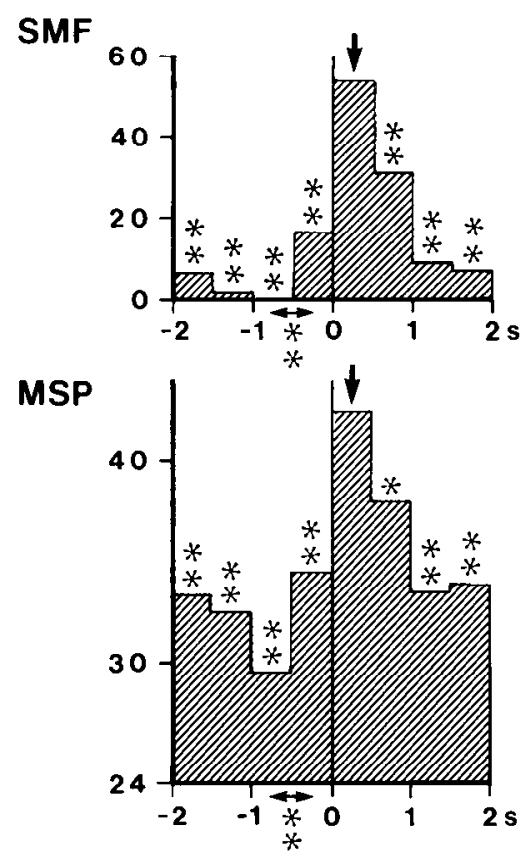

Figure 8. Group analysis of burst-spindle relations in a sample of 334 bursts from 14 cells (selection criteria in text). Top graph shows medians of sequential mean frequencies $(S M F)$ in eight $0.5 \mathrm{sec}$ bins; time 0 is start of burst. Bottom graph shows medians of relative amplitudes of filtered spindle waves $(M S P ; 7-14 \mathrm{~Hz})$ recorded simultaneously through the same microelectrodes in RE nucleus. Comparisons were made, for both unit discharges and spindle waves, between the first $0.5 \mathrm{sec}$ bin after burst onset (arrows) and all preceding and subsequent bins. In addition, the two bins preceding burst onset were compared. Significantly increased discharge rates and spindle-wave amplitudes are indicated by double $(p \leq 0.01)$ and single $(p \leq 0.05)$ asterisks (paired Wilcoxon tests). 


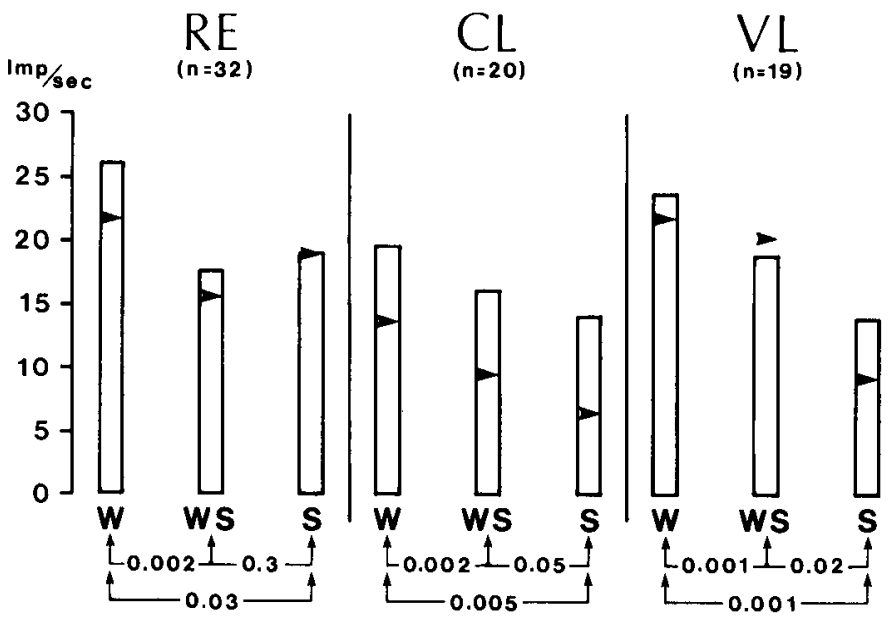

Figure 9. Mean (columns) and median (arrowheads) firing rates of 32 RE neurons and 20 thalamocortical $C L$ and 19 VL neurons during W, $S$, and transitional WS state. Significance levels are from Wilcoxon paired sign-rank tests.

was dispersed between 50 and $150 \mathrm{msec}$. During $\mathrm{S}$, the latency mode lengthened to $15-20 \mathrm{msec}$ and the duration of the evoked burst increased, reaching $50 \mathrm{msec}$. By and large, this aspect resembles the state-dependent changes in cortically evoked discharges (see Fig. 11). (2) The remaining five RE neurons lacked the MRF-evoked short-latency excitation. Instead, a period of suppressed firing was observed, with a latency of 5-10 $\mathrm{msec}$ and a duration of $20-25 \mathrm{msec}$ (Fig. 14). Thereafter, an increase in discharge frequencies, as compared to prestimulus values, lasted for 50-150 msec.

\section{Discussion}

We shall discuss two groups of salient findings in our experiments and suggest some implications for the nature of relations between RE neurons and cells in other thalamic nuclei.

\section{$R E$ bursts and spindle waves}

The thalamus is the source of the rhythmicity of synchronized EEG waves during S sleep, as shown by survival of the spindle rhythm in the intralaminar region after bilateral decortication and high brain stem transection (Morison and Bassett, 1945). It was recently shown, in both barbiturated and unanesthetized preparations, that spindle sequences of thalamocortical neurons (consisting of $7-14 \mathrm{~Hz}$ oscillations that last for $1-1.5 \mathrm{sec}$ ) recur periodically with a slow rhythm of $0.1-0.2 \mathrm{~Hz}$ (Deschênes et al., 1984; Steriade and Deschênes, 1984). The present experiments have shown that both spindle-related rhythms $(7-14 \mathrm{~Hz}$ and $0.1-0.2 \mathrm{~Hz}$ ) do appear in RE nucleus during drowsiness and $\mathrm{S}$ sleep, and that they are significantly related to spike barrages of RE neurons. Below, we deal with the basic differences between the activity patterns of RE and thalamocortical neurons during spindling revealed by comparing our data with previous studies on thalamic relay cells.

In thalamocortical neurons, the prominent events during a

\section{SMF}

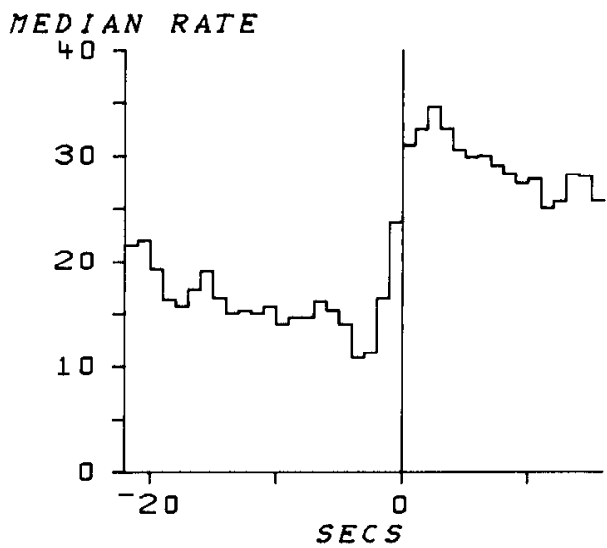

CSA

Figure 10. Group analysis of median discharge rates of RE neurons and median focal and cortical EEG amplitudes on arousal from $S$ sleep; 14 neurons recorded during $24 \mathrm{~S} \rightarrow$ W transitions. Sequential mean frequencies of RE discharges (SMF, top left) are depicted along with simultaneously recorded focal $\mathrm{RE}$ spindle waves $(M S P$, filtered $7-14 \mathrm{~Hz})$ as well as cortical slow-waves $(C S \Delta, 0.5-4 \mathrm{~Hz})$ and cortical spindles $(C S P, 7-14 \mathrm{~Hz})$. Time 0 is arousal from $S$, as indicated by the first sign of decreased amplitude of EEG rhythms. Median rates and amplitudes were computed on a bin-by-bin basis (1 sec bins).

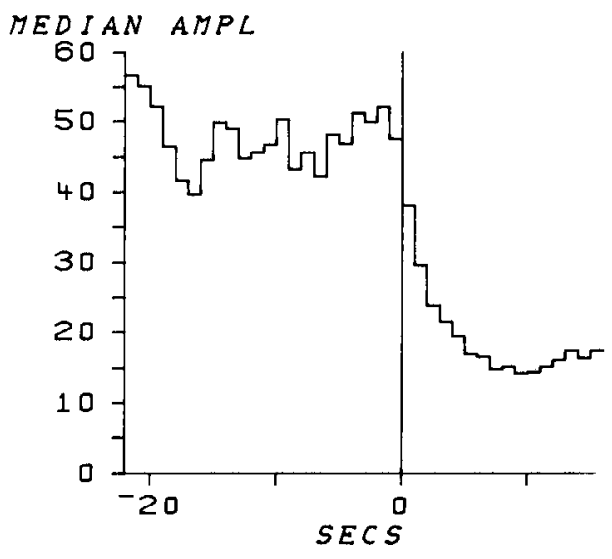

$M S P$

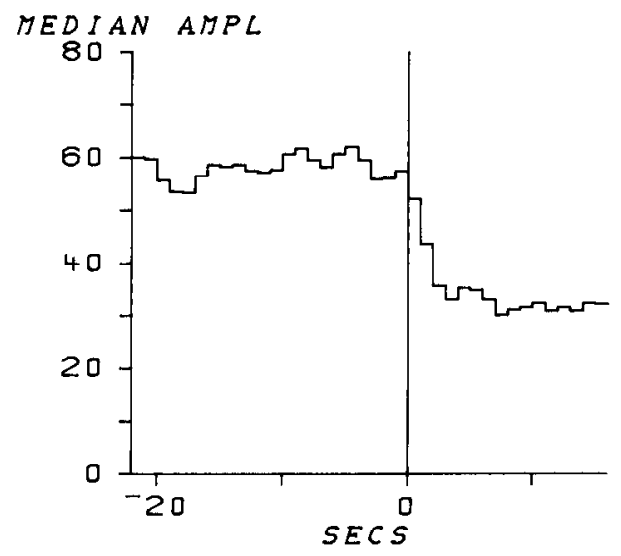

CSP

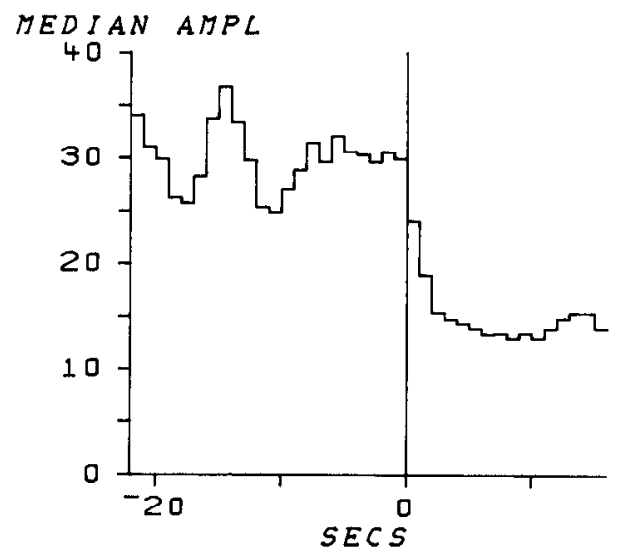


spindle sequence are cyclic, long-lasting (100-150 msec) hyperpolarizations whose polarity could be reversed by current and $\mathrm{Cl}^{-}$injections, indicating that they consist mainly of rhythmic IPSPs (Andersen and Sears, 1964; Deschênes et al., 1984; Maekawa and Purpura, 1967). The discharge bursts that occasionally interrupt hyperpolarizations are time- and voltage-dependent events deinactivated by membrane hyperpolarization (Deschênes et al., 1984; Jahnsen and Llinás, 1984). The ionic basis of the postinhibitory rebound is a slow $\mathrm{Ca}^{2+}$ spike that underlies fast repetitive $\mathrm{Na}^{+}$action potentials (Llinás and Jahnsen, 1982). The postinhibitory bursts of thalamic relay cells are highly structured and characterized by short durations $(10-25 \mathrm{msec})$, intraburst frequencies above $250-300 \mathrm{~Hz}$, and, within each burst, successive interspike intervals with each longer than the preceding one. During natural $\mathbf{S}$ sleep, this pattern is common to thalamocortical neurons in both relay (McCarley et al., 1983) and intralaminar (Glenn and Steriade, 1982) nuclei.

In RE neurons, the bursts have lower frequencies and variable accelerando-ritardando patterns that distinguish them from the stereotyped bursts of relay cells. It is likely that the long-lasting spike barrages of RE neurons, which display, in the unanesthetized condition, diverse patterns of decreasing and increasing durations of interspike intervals (Fig. 4), followed by a long tonic tail (Fig. $5 A$ ), are generated by a more complex set of conductances than those of relay neurons. We have demonstrated that RE neurons discharge with prolonged barrages that extend over the whole period of the focal spindle sequence simultaneously recorded in the RE nucleus. This result suggests that RE neurons are depolarized throughout the spindle sequence, with oscillations within the same frequency but of opposite polarity as compared to thalamocortical neurons.

\section{Increased excitation of $R E$ neurons on arousal}

Our results indicate that changes in RE neuronal activities on arousal and throughout the W state parallel those of thalamocortical cells.

Thalamic relay neurons tonically increase their rates of spontaneous firing during $\mathrm{W}$ compared to S sleep. Similarly, the increase in discharge rates of RE neurons during $W$ is statistically significant, and their tonic discharge patterns during this state resemble those of relay cells. In this respect, our data fit previous data on rostral RE neurons in encéphale isolé preparations (Steriade and Wyzinski, 1972) and perigeniculate RE neurons in behaving animals (Barrionuevo et al., 1981; Mukhametov et al., 1970). Most important for the issue of arousal-related changes, we dissociated various epochs within the W state and established that the highest firing rates occur during the initial period of awakening from $S$ sleep, with a subsequent slowdown of discharges during later, more relaxed epochs of $\mathrm{W}$ approaching drowsiness.

The striking increase in spontaneous firing rates on natural arousal is consistent with the effects of MRF stimulation in a majority of tested RE neurons. Discharges with latencies of 45 msec during W (Fig. 13) may be ascribed to direct MRF-RE projections (Edwards and De Olmos, 1976; Moon-Edley and Graybiel, 1983), knowing the slow conduction velocities of rostrally projecting MRF neurons (Ropert and Steriade, 1981) and that the EPSPs underlying RE discharges start earlier. The failure to detect this short-latency excitation in previous studies that instead reported long-duration suppression of RE firing may be due to costimulation of passing fibers issuing from locus coeruleus or other monoaminergic systems exerting hyperpolarizing actions at their targets. The chronic lesions in the present experiments largely avoided this complicating factor. In some RE neurons, a period of diminished or suppressed firing was detected after MRF stimuli, roughly corresponding to the period of initial excitation in the other RE neurons. One may envisage,
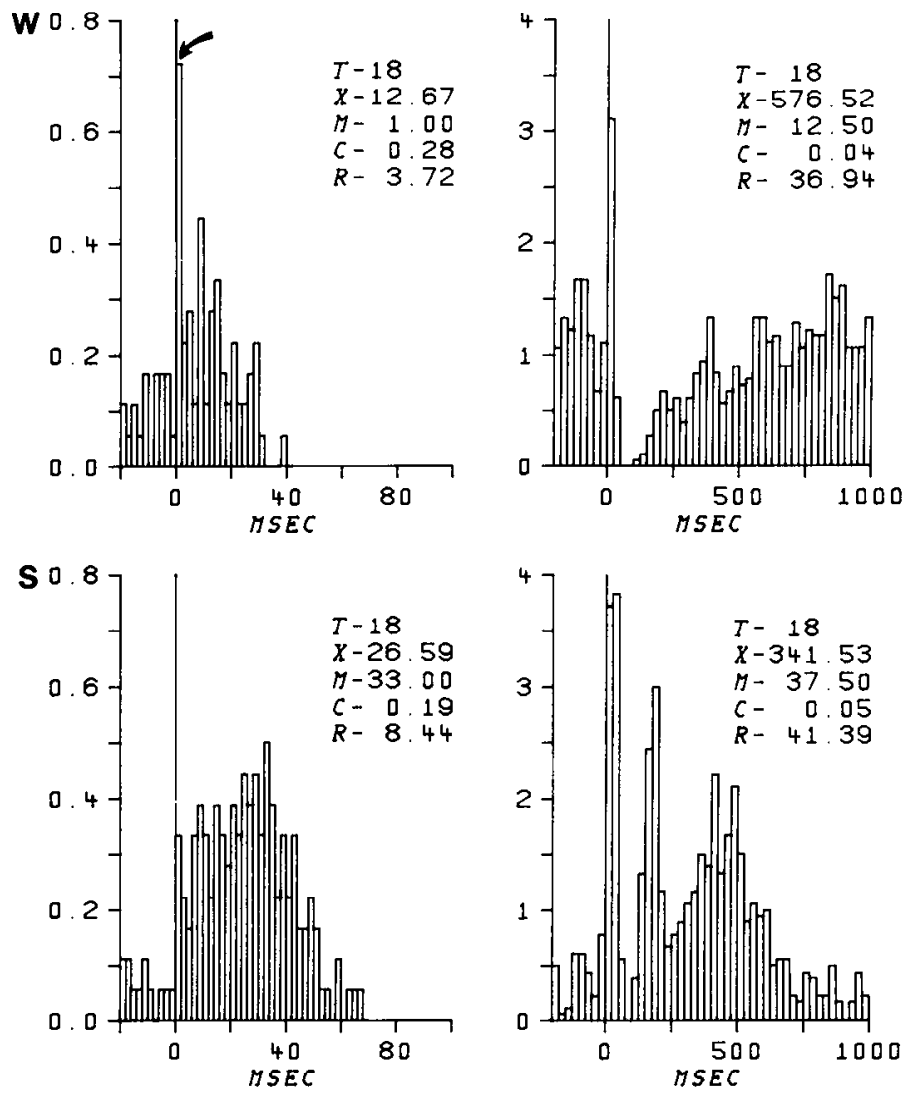

Figure 11. Peristimulus histograms (PSH) of cortically evoked activities in a neuron recorded from the rostral pole of RE nucleus during $\mathrm{W}$ and S. Single shock to the precruciate gyrus applied at time 0 . Two PSHs are depicted for each state, one with $2 \mathrm{msec}$ bins (left) and another with $25 \mathrm{msec}$ bins (right), to show details of the early and late events. Symbols in PSHs are the same as used in Figure 3A. Oblique arrow, top left PSH points to the increased probability of early evoked discharges ( $<2$ msec latency) during $W$.

on the basis of intra-RE axonal collateralization and symmetric dendrodendritic synapses with pleomorphic vesicles in the cat RE nucleus (Deschenes et al., 1985) that MRF-evoked orthodromic excitation in a group of RE neurons leads to hyperpolarization in synaptically coupled RE cells. Similar phenomena may occur when stimulating the MRF by antidromic activation of RE-MRF axons (Parent and Steriade, 1984). It should be noted, however, that the period of diminished or suppressed firing in RE neurons was short-lasting $(25 \mathrm{msec})$ and was followed by a clear, long-lasting excitation.

The evidence plainly indicates that natural arousal and wakesleep transitions are associated with similar changes in RE and rostrally projecting MRF neurons. The RE neurons significantly decrease discharge rates from $W$ to $S$ and increase firing rates on arousal from S (Figs. 9 and 10), as do MRF neurons (Oakson and Steriade, 1983; Steriade et al., 1982).

The increased background firing on arousal is accompanied in RE neurons by an enhanced synaptic excitability, as indicated by the two- or threefold increase in probability of cortically or MRF-evoked discharges at short latencies. The histograms in Figures 11 and 13 suggest that the underlying EPSPs are much faster-rising and shorter-lasting during $\mathrm{W}$ as compared to $\mathrm{S}$. Similar features have been reported during the tonic and bursting modes of thalamocortical neurons recorded from intralaminar (Glenn and Steriade, 1982) and ventromedial (Macl eod and James, 1984) nuclei. 
Figure 12. Location of stimulating electrodes in rostral part of midbrain reticular formation (MRF) $(A)$, chronic lesions of locus coeruleus $(B)$, and caudal midbrain tegmentum $(C)$ to ascertain that evoked responses in RE neurons were transmitted through pathways from MRF cell bodies after degeneration of passing fibers. Frontal sections at A 3.7 (A), P 2.8 $(B)$ and A 0.5 (C). $C G$, Central gray; $C S$, nucleus raphe centralis superior; FTC, central tegmental field of MRF; FTG, gigantocellular pontine field; FTP, paralemniscal tegmental field; $I P$, interpeduncular nucleus; $L C$, nucleus raphe linearis centralis; $P B G$, parabigeminal nucleus; $R N$, red nucleus; $S C$, superior colliculus; $S N C$, substantia nigra pars compacta; $T B$, trapezoidal body; $V 4$, fourth ventricle; $3 N$, nucleus of the third nerve.
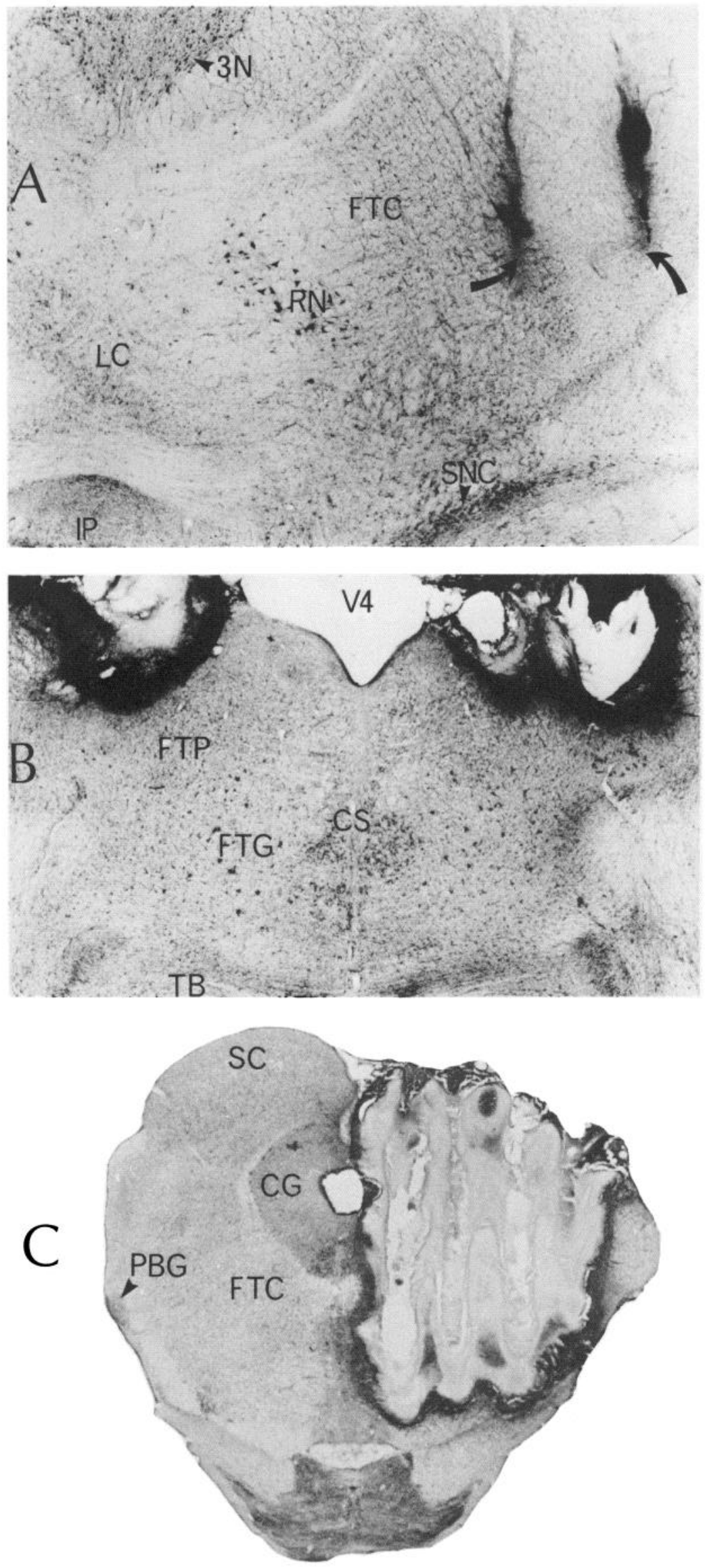

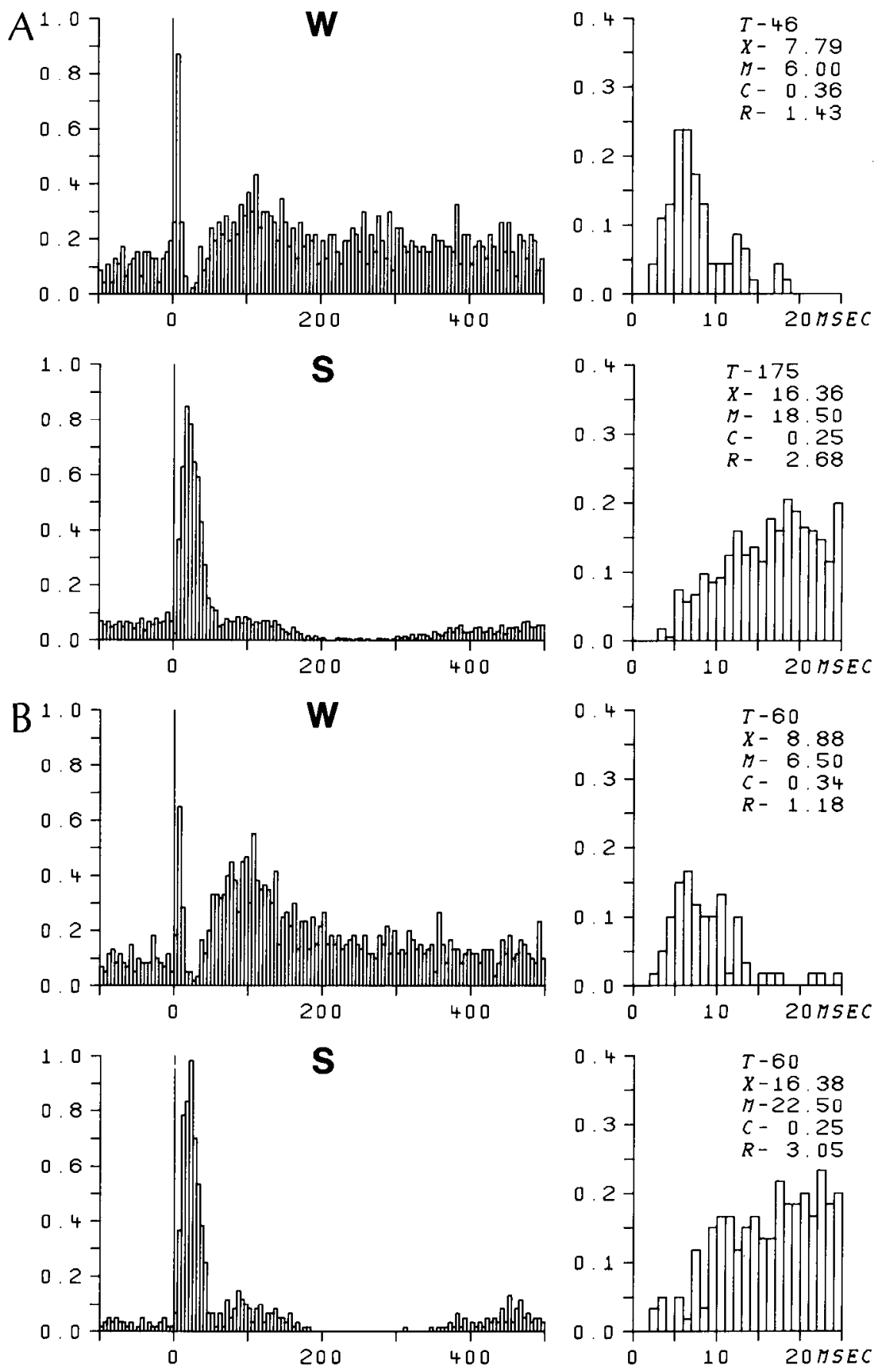

Figure 13. Short-latency excitation elicited by MRF stimulation in two $(A, B)$ rostral RE neurons. Two $3 \mathrm{msec}-$ delayed shocks applied at time 0 (stimulus artifacts deleted from PSH). For both neurons, two PSHs are depicted in each behavioral state of $\mathrm{W}$ and $\mathrm{S}$ (left PSH with $5 \mathrm{msec}$ bins, right $P S H$ with 1 msec bins). Symbols as in Figure 3A. Description in text.

Remarks on relations between $R E$ and other thalamic cell classes

In any hypothesized relation between inhibitory and inhibited neuronal pools, one expects mirror images in activities of the two cellular groups under consideration. For example, the discharge rates of GABAergic substantia nigra cells decrease, and those in their superior collicular targets increase in relation to saccadic eye movements (Hikosaka and Wurtz, 1983). The nature of relations between RE and thalamocortical neurons appears more complex, judging from present results and from recent immunohistochemical and electron-microscopic studies.

During S sleep, the protracted excitation of RE neurons extending over a whole spindle sequence may indeed be regarded as the probable source for spindle-related hyperpolarizations in thalamocortical neurons. This view is supported by recent experiments. In the cat, the only thalamic nuclei that are naturally deprived of inputs from RE nucleus are anterior nuclei (Steriade et al., 1984). Correlatively, spontaneous and evoked spindle oscillations are absent in cortically projecting anterior thalamic neurons, in spite of the fact that their electrophysiological properties are similar to those of thalamocortical neurons in other nuclei (Mulle et al., 1985). After acute transections disconnecting the dorsal thalamus from the RE nucleus, or chronic kainate lesions of the RE nucleus, spindling is abolished in relay and intralaminar thalamic nuclei (Steriade et al., 1985). During W, however, parallelism rather than reciprocity was found between RE and thalamocortical neurons by investigating both spontaneous and evoked discharges. The dramatic increase in firing 

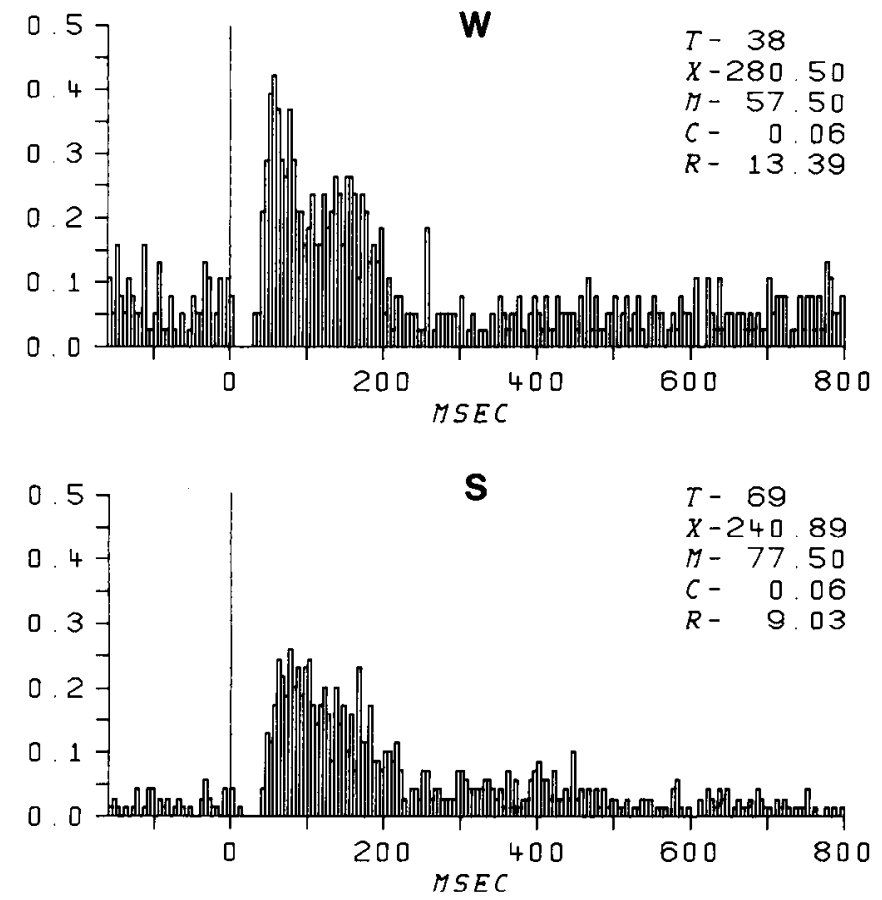

Figure 14. Initially suppressed firing and subsequent excitation induced by MRF stimulation in a rostrolateral RE cell during $W$ and $S$ states. Three $2.5 \mathrm{msec}$-delayed shocks (stimulus artifacts deleted). PSHs with $5 \mathrm{msec}$ bins. Symbols as in Figure $3 A$.

rates of RE neurons on awakening, with tonic discharges reaching $50-100 / \mathrm{sec}$ during the initial period of arousal, is especially hardly compatible with hypothesized inhibitory actions of RE cells upon thalamocortical neurons, since the latter simultaneously increase their firing rates and display an enhanced somatic and dendritic excitability, as tested by antidromic and orthodromic volleys (Glenn and Steriade, 1982; Steriade et al., 1971, 1977).

These different pictures of activity fluctuations in RE and thalamocortical neurons during $S$ and $W$ (reciprocal images and similar aspects, respectively) would be difficult to interpret in a simple circuitry involving only these two cellular classes unless we speculate that the two probable transmitters of RE neurons, GABA and somatostatin (Graybiel and Elde, 1983; Oertel et al., 1983), are used differently in $S$ and $W$. If the depolarizing actions and decreased amplitudes of IPSPs induced by somatostatin on cortical neurons (Delphs and Dichter, 1983) were similarly exerted in the thalamus, one could hypothesize that GABA is predominantly released in $\mathrm{S}$ and somatostatin in $\mathrm{W}$. While remote, this possibility should be tested.

To stay on more solid ground, we call upon the recent discovery that, in the extraglomerular neuropil, synaptic profiles of RE origin contact not only dendrites of thalamocortical neurons, but also presynaptic dendrites of GABAergic local-circuit neurons (Montero and Singer, 1985). The influences of GABA-ergic RE neurons upon GABAergic local interneurons may be more powerful than those exerted upon thalamocortical neurons, taking into consideration that, in other central structures, GABAergic neurons are 20 times more sensitive to GABA than other elements (Grace and Bunney, 1979, 1985). The idea of a powerful RE inhibition upon thalamic inhibitory interneurons is supported by our recent experiments. The disconnection of thalamocortical neurons from their RE inputs led not only to abolition of their spindle oscillations, but also to an all-burst activity - a pattern reflecting continuous inhibitory actions from local-circuit GABAergic cells, which was blocked by bicuculline (Steriade et al., 1985). Therefore, effective inhibition for generating burst discharges is more manifest in RE-deprived thalamic nuclei than in the intact thalamus, suggesting released activity of short-axoned GABAergic neurons following RE disconnection.

We assume that the different patterns of discharges in RE axons during $W$ and $S$ (Fig. 4) lead to various amounts of GABA release, with consequent state-dependent changes in ratios between inhibitory actions upon local-circuit cells and those upon thalamocortical neurons. During $W$, associated with tonic firing of RE neurons, the higher sensitivity of GABAergic interneurons to GABA, compared to that of relay cells, would result in enhanced excitability of thalamocortical neurons through their disinhibition. During $S$, RE neurons reach peak intraburst frequencies higher than the fastest tonic discharges in $\mathrm{W}$. It was demonstrated that the amounts of released GABA increase with the number of impulses in an identified inhibitory nerve (Otsuka et al., 1966). The increase activity in presynaptic RE axons would greatly increase the efficacy of inhibitory actions upon thalamocortical neurons. On the other hand, however, GABA receptors of the more sensitive GABAergic local-circuit neurons would be saturated; it is known that an overabundance of transmitter leads to a decreased receptor sensitivity (see Enna and Gallagher, 1983, for a review). The overt effects resulting from these interactions would be a prevalent inhibition exerted by RE neurons upon thalamocortical neurons during $S$ (with the consequence of cyclic hyperpolarizations of relay neurons associated with spindling) and a prevalent inhibition exerted by RE neurons upon local-circuit neurons during $W$ (with the consequence of increased excitability of relay neurons on awakening).

If the inhibition of relay neurons by RE neurons during $S$ is in line with current concepts, the parallel excitation of these two cell classes on arousal is unexpected. We suggest that, during $\mathrm{W}$, when increased firing occurs in circumscribed thalamocortical projections, directly connected RE neurons contribute to further enhancing this relevant activity by inhibiting the local pool of intrinsic GABAergic elements. ${ }^{1}$ Simultaneously, the activity in adjacent RE zones will be suppressed by axonal collateralization within the nucleus, with the consequence of released activity of local-circuit neurons and inhibition of weakly excited relay neurons in thalamic areas adjacent to the active thalamic focus.

\section{References}

Andersen, P., and T. A. Sears (1964) The role of inhibition in the phasing of spontaneous thalamo-cortical discharge. J. Physiol. (Lond.) 173: 459-480.

Barrionuevo, G., O. Benoit, and P. Tempier (1981) Evidence for two types of firing pattern during the sleep-walking cycle in the reticular thalamic nucleus of the cat. Exp. Neurol. 72: 486-501.

Crick, F. (1984) The function of the thalamic reticular complex: The searchlight hypothesis. Proc. Natl. Acad. Sci. USA 81: 4586-4590.

Delphs, J. R., and M. A. Dichter (1983) Effects of somatostatin on

\footnotetext{
' Enhancement of activity in thalamocortical neurons by positive feedback from RF, neurons was similarly suggested by Crick (1984). The postulated mechanism was different from that outlined above because the synaptic contacts between RE and GABAergic local-circuit cells (Montero and Singer, 1985) were not known at that time. Crick assumed that enhanced activity in patches of thalamocortical cells would appear as high-frequency bursts after hyperpolarization. The bursts of relay (McCarley et al., 1983) and intralaminar (Glenn and Steriade, 1982) thalamic neurons are, however, state-specific: they are most frequent in $S$ and very rarely occur in $\mathbf{W}$. Indeed, thalamocortical neurons become hyperpolarized as the animal shifts from $W$ to $S$ (Hirsch et al., 1983). The attentional searchlight occurs in W, a state in which thalamic relay neurons are tonically depolarized, as evidenced for example, in the probability enhancement of antidromic invasion (see above).
} 
mammalian cortical neurons in culture: Physiological actions and unusual dose response characteristics. J. Neurosci. 3: 1176-1188.

Deschênes, M., A. Madariaga-Domich, and M. Steriade (1985) Dendrodendritic synapses in the cat reticularis thalami nucleus: A structural basis for thalamic spindle synchronization. Brain Res. 334: 165168.

Deschênes, M., M. Paradis, J. P. Roy, and M. Steriade (1984) Electrophysiology of neurons of lateral thalamic nuclei in cat: Resting properties and burst discharges. J. Neurophysiol. 51: 1196-1219.

Edwards, S. B., and J. S. De Olmos (1976) Autoradiographic studies of the projections of the midbrain reticular formation: Ascending projections of nucleus cuneiformis. J. Comp. Neurol. 165: 417-432.

Enna, S. J., and J. P. Gallagher (1983) Biochemical and electrophysiological characteristics of mammalian GABA receptors. Int. Rev. Neurobiol. 24: 181-212.

Glenn, L. L., and M. Steriade (1982) Discharge rate and excitability of cortically-projecting neurons in the intralaminar thalamic nuclei during waking and sleep states. J. Neurosci. 2: 1387-1404.

Grace, A. A., and B. S. Bunney (1979) Paradoxical GABA excitation of nigral dopamincrgic cells: Indirect mediation through reticulata inhibitory neurons. Eur. J. Pharmacol. 59: 211-218.

Grace, A. A., and B.S. Bunney (1985) Opposing effects of striatonigral feedback pathways on midbrain dopamine cell activity. Brain Res. 333: 271-284.

Graybiel, A. M., and R. P. Elde (1983) Somatostatin-like immunoreactivity characterizes neurons of the nucleus reticularis thalami in the cat and monkey. J. Neurosci. 3: 1308-1321.

Hikosaka, O., and R. H. Wurtz (1983) Visual and oculomotor functions of monkey substantia nigra pars reticulata. IV. Relation of substantia nigra to superior colliculus. J. Neurophysiol. 49: 1285-1301.

Hirsch, J. C., A. Fourment, and M. E. Marc (1983) Sleep-related variations of membrane potential in the lateral geniculate body relay neurons of the cat. Brain Res. 259: 308-312.

Houser, C. R., J. E. Vaughn, R. P. Barber, and E. Roberts (1980) GABA neurons are the major cell type of the nucleus reticularis thalami. Brain Res. 200: 341-354.

Jahnsen, H., and R. Llinás (1984) Electrophysiological properties of guinea-pig thalamic neurones: An in vitro study. J. Physiol. (Lond.) 349: 205-226.

Jones, E. (1975) Some aspects of the organization of the thalamic reticular complex. J. Comp. Neurol. 162: 285-308.

Llinás, R., and H. Jahnsen (1982) Electrophysiology of mammalian thalamic neurones in vitro. Nature 297: 406-408.

MacLeod, N. K., and T. A. James (1984) Regulation of cerebellocortical transmission in the rat ventromedial thalamic nucleus. Exp. Brain Res. 55: 535-552.

Maekawa, K., and D. P. Purpura (1967) Properties of spontaneous and evoked synaptic activitics of thalamic ventrobasal neurons. $J$. Neurophysiol. 30: 360-381.

Massion, J., P. Angaut, and D. Albe-Fessard (1965) Activités evoquées chez le chat dans la région du nucleus ventralis lateralis. II. Etude microphysiologique. Electroenceph. Clin. Neurophysiol. 19: 452-469.

McCarley, R. W., O. Benoit, and G. Barrionuevo (1983) Lateral geniculate nucleus unitary discharge in sleep and waking: State and rate specific aspects. J. Neurophysiol. 50: 798-818.

Montero, V.M. (1983) Ultrastructural identification of axon terminals from the thalamic reticular nucleus in the medial geniculate body in the rat: An EM autoradiographic study. Exp. Brain Res. 51:338-342.

Montero, V. M., and G. L. Scott (1981) Synaptic terminals in the dorsal lateral geniculate nucleus from neurons of the thalamic reticular nucleus: A light and electron microscope autoradiographic study. Neuroscience 6: 2561-2577.

Montero, V. M., and W. Singer (1985) Ultrastructural identification of somata and neural processes immunoreactive to antibodies against glutamic acid decarboxylase (GAD) in the dorsal lateral geniculate nucleus of the cat. Exp. Brain Res. 59: 151-165.

Moon-Edley, S., and A. M. Graybiel (1983) The afferent and efferent connections of the feline nucleus tegmenti pedunculopontinus, pars compacta. J. Comp. Neurol. 217: 187-215.

Morison, R. S., and D. L. Bassett (1945) Electrical activity of the thalamus and basal ganglia in decorticate cats. J. Neurophysiol. 8: 309-314.
Mukhametov, L. M., G. Rizzolatti, and V. Tradardi (1970) Spontaneous activity of nucleus reticularis thalami in freely moving cats. $J$. Physiol. (I. ond.) 210:651-667.

Mulle, C., M. Steriade, and M. Deschênes (198: Absence of spindle oscillations in the cat anterior thalamic nuclei. Brain Res. 334: 169171.

Negishi, K., S. E. Lu, and M. Verzeano (1962) Neuronal activity in the lateral geniculate body and the nucleus reticularis of the thalamus. Vision Res. 1: 343-353.

Oakson, G., and M. Steriade (1983) Slow rhythmic oscillations of EEG slow-wave amplitudes and their relations to midbrain reticular discharge. Brain Res. 269: 386-390.

Oertel, W. H., A. M. Graybiel, E. Mugnani, R. P. Elde, D. E. Schmechel, and I. J. Kopin (1983) Coexistence of glutamic acid decarboxylase and somatostatin-like immunoreactivity in neurons of the feline nucleus reticularis thalami. J. Neurosci. 3: 1322-1332.

Ohara, P. T., A. R. Liebermann, S. P. Hunt, and J. Y. Wu (1983) Neural elements containing glutamic acid decarboxylase (GAD) in the dorsal lateral geniculate nucleus of the rat; immunohistochemical studies by light and electron microscopy. Neuroscience 8 ; 189-211.

Ohara, P. T., A. J. Sefton, and A. R. Liebermann (1980) Mode of termination of afferents from the thalamic reticular nucleus in the dorsal lateral geniculate nucleus of the rat. Brain Res. 197: 503-506.

Otsuka, M., L. L. Iversen, Z. W. Hall, and E. A. Kravitz (1966) Release of gamma-aminobutyric acid from inhibitory nerves of lobster. Proc. Natl. Acad. Sci. USA 56: 1110-1115.

Parent, A., and M. Steriade (1984) Midbrain tegmental projections of nucleus reticularis thalami of cat and monkey: A retrograde transport and antidromic invasion study. J. Comp. Neurol. 229: 548-558.

Pechansky, M., H. J. Ralston, and F. Roudier (1983) Reticularis thalami afferents to the ventrobasal complex of the rat thalamus: An electron microscope study. Brain Res. 270: 325-329.

Purpura, D. P., and R. J. Shofer (1963) Intracellular recording from thalamic ncurons during reticulocortical activation. J. Neurophysiol. 26: 494-505.

Ramón y Cajal, S. (1911) Histologie du Système Nerveux de l'Homme et des Vertébrés, Vol. 2, Maloine, Paris.

Ropert, N., and M. Steriade (1981) Input-output organization of midbrain reticular core. J. Neurophysiol. 46: 17-31.

Scheibel, M. E., and A. B. Scheibel (1966) The organization of the nucleus reticularis thalami: A Golgi study. Brain Res. 1: 43-62.

Scheibel, M. E., and A. B. Scheibel (1967) Structural organization of nonspecific thalamic nuclei and their projection toward cortex. Brain Res. 6: 60-94.

Schlag, J., and M. Waszak (1971) Electrophysiological properties of units of the thalamic reticular complex. Exp. Neurol. 32: 79-97.

Steriade, M., and M. Deschênes (1984) The thalamus as a neuronal oscillator. Brain Res. Rcv. 8: 1-63.

Steriade, M., and L. L. Glenn (1982) The neocortical and caudate projections of intralaminar thalamic neurons and their synaptic excitation from the midbrain reticular core. J. Neurophysiol. 48: 352371 .

Steriade, M., and P. Wyzinski (1972) Cortically evoked activities in thalamic reticularis neurons. Brain Res. 42: 514-520.

Steriade, M., V. Apostol, and G. Oakson (1971) Control of unitary activities in cerebellothalamic pathways during wakefulness and synchronized sleep. J. Neurophysiol. 34: 384-413.

Steriade, M., M. Deschênes, L. Domich, and C. Mulle (1985) Abolition of spindle oscillations in thalamic neurons disconnected from nucleus reticularis thalami. J. Neurophysiol. 54: 1473-1497.

Steriade, M., G. Oakson, and A. Diallo (1977) Reticular influences on lateralis postcrior thalamic ncurons. Brain Res. 131: 55-71.

Steriade, M., G. Oakson, and N. Ropert (1982) Firing rates and patterns of midbrain reticular neurons during steady and transitional states of the sleep-waking cycle. Exp. Brain Res. 46: 37-51.

Steriade, M., A. Parent, and J. Hada (1984) Thalamic projections of nucleus reticularis thalami of cat: $A$ study using retrograde transport of horseradish peroxidase and double fluorescent tracers. J. Comp. Neurol. 229: 531-547

Waszak, M. (1974) Effect of barbiturate anesthesia on discharge pattern in nucleus reticularis thalami. Pharmacol. Biochem. Behav 2. 339-345. 